\title{
O Assédio Moral na Relação de Emprego
}

\section{Moral Harassment in the Employment Relationship}

\author{
Tulio Marques Carvalho Ferreira
}

Faculdade Pitágoras de Marabá. PA, Brasil.

E-mail: tulio.ferreira@kroton.com.br

\begin{abstract}
Resumo
O presente artigo científico visa tratar o fenômeno do assédio moral na relação de emprego. Esta conduta de prática ilícita traz consequências para o empregado, tendo os seus direitos fundamentais e a dignidade da pessoa humana violada. $\mathrm{O}$ assédio moral configura como conduta repetitiva e abusiva que atenta contra a integridade e dignidade da pessoa humana no ambiente de trabalho. Este fenômeno submete o empregado a perseguições, humilhações e maus tratos afetando a saúde física e psicológica do empregado. Nesse sentido se defende a valorização do empregado, que tem direito a um ambiente de trabalho sadio, prevenindo-se deste fenômeno que afeta o empregado. Geralmente, o empregado, o sujeito passivo assediado tem direito de pedir indenização do sujeito ativo (quem cometeu o assédio). Na legislação brasileira não há previsão com normas específicas sobre o assunto, mas os Tribunais trabalhistas buscam o amparo no texto Maior e nos Códigos civil e penal e na Consolidação das Leis Trabalhistas, tendo o julgador que observar o princípio da razoabilidade e proporcionalidade. No intuito de seguir as prerrogativas estabelecidas neste trabalho, baseando-se nos objetivos de analisar as noções do assédio moral, conceituação, as condutas que configuram tal agressão, os sujeitos e os tipos de assédio. A problemática se especificou em como evitar a prática desta conduta na relação de emprego. Por sua vez, a metodologia utilizada para averiguar este trabalho foi de ordem bibliográfica, fundamentando-se no acervo bibliográfico, a fim de ter conhecimento de como é tratado o assunto pela lei, doutrina e artigos científicos, obtendo-se maior conhecimento sobre o assunto.
\end{abstract}

Palavras-chave. Assédio Moral. Relação de Emprego. Ambiente de Trabalho. Humilhações.

\begin{abstract}
This scientific Article aims to address the phenomenon of moral harassment in the employment relationship. This unlawful practice conduct has consequences for the employee, having his or fundamental rights and the dignity of the violated human person. Moral harassment is a repetitive and abusive conduct that is attentive to the human person integrity and dignity in the working environment. This phenomenon subjects the employee to persecution, humiliation and ill-treatment affecting the employee's physical and psychological health. In this sense, the employee's appreciation is defended, which has the right to a healthy working environment, preventing this phenomenon that affects the employee. Generally, the employee, the harassed person has the right to seek compensation from the harasser (who committed the harassment). In the Brazilian legislation there is no provision for specific rules on the subject, but the Labor courts seek support in larger text and in civil and criminal codes and in the Labor laws consolidation, with the judging party observing the principle of reasonableness and proportionality. In order to follow the prerogatives established in this paper, the objectives were based on the analysis on notions of moral harassment, conceptualization, the conducts that constitute such aggression, the subjects and the types of harassment. The problem has been made clear on how to avoid the practice of this conduct in the employment relationship. In turn, the methodology used to investigate this work was bibliographic, based on the bibliographic collection, in order to know how the subject is treated by law, doctrine and scientific articles, obtaining greater knowledge about the matter.
\end{abstract}

Keywords. Moral harassment. Employment relationship. Work Environment. Humiliation

\section{Introdução}

O assédio moral na relação de emprego vem ganhando muito destaque nos últimos anos, mas sua constatação pode ser observada no trabalho assalariado. Este fenômeno tornouse uma forte preocupação social, pois provoca muito desgaste pelos impactos que atinge a saúde do trabalhador no ambiente de trabalho.

Este trabalho abordará, de maneira objetiva, o assédio moral na relação de emprego, este fenômeno que atinge a reputação e a dignidade da pessoa humana. O assédio moral, em linhas gerais, é tido com conduta abusiva, sendo caracterizado através de palavras, gestos e comportamentos que atentem contra a dignidade e a integridade de uma pessoa.

Observa-se que a configuração do assédio deve envolver os sujeitos, sendo aquele que assedia conhecido como sujeito ativo, e aquele que sofre as humilhações e agressões tido como sujeito passivo.

\section{Desenvolvimento}

\subsection{Metodologia}

A metodologia escolhida como ferramenta de captação de conteúdo principal foi a pesquisa bibliográfica, tendo em vista que se trata de trabalho elaborado como base em bibliografia, artigos científicos, e legislação nacional. Não destarte, far- 
se-á pesquisa exploratória nos mais diversos documentos jurisprudenciais, livros, artigos científicos.

Buscando na pesquisa bibliográfica o embasamento teórico, pois a mesma busca explicar um problema a partir de referências teóricas publicadas em artigos, livros, dissertações e teses. Pode ser realizada independentemente ou como parte de pesquisa descritiva. Dessa forma, nos dois tipos se busca conhecer e analisar os benefícios, tanto na área social, cultural e científica dos antecedentes históricos sobre determinado assunto, tema ou problema.

\subsection{Noções sobre o Assédio Moral}

O assédio moral é existente desde a origem da relação de trabalho, só que de formas diferentes da atualidade, praticadas nos ambientes de trabalho. Este tipo de assédio está sendo visto como um terror psicológico, atingindo as suas vítimas física e mentalmente, podendo ocasionar várias doenças até morte, dependendo do grau que se chega.

O fenômeno assédio moral pode ser entendido como uma violência ocasionada entre pessoas, muitas vezes ocorrendo fora do ambiente de trabalho, com danos muitas vezes irreparáveis para a vida do trabalhador (HIRIGOYEN, 2002, p.50).

Nesse sentido, o assédio, para ser configurado, deve pressupor a existência do agressor, que é o responsável pela conduta assediante e do outro lado a vítima que recebe as agressões.

O assédio moral é entendido como mobbing, uma palavra nova dentro do ordenamento jurídico, mas sua ocorrência é antiga e bastante praticada. A expressão mobbing advém do verbo inglês to mob, tendo sua tradução como: atacar, perseguir, maltratar. Para Hirigoyen (2002, p.50):

Foi presumivelmente utilizado pela primeira vez pelo etnólogo Konrad Lorenz, a propósito do comportamento agressivo de animais que querem expulsar um animal intruso, e reproduzido nos anos 60 pelo médico sueco, Peter Heinemann, para descrever o comportamento hostil de determinadas crianças em relação a outras, dentro das escolas. Em 1972, ele publicou o primeiro livro sobre mobbing, o qual trata da violência de um grupo de crianças.

Observa-se que, no cenário mundial, no qual existe uma competição de mercado e produtividade de baixo custo, sendo marcado pela insensibilidade de dirigentes e pelo intuito de atingir metas e os resultados previstos, sem observância do bem-estar do trabalhador.

No cotidiano de extensão e celeridade dos meios de produção, as empresas em busca de resultados rápidos, às vezes, atingem a intimidade e dignidade do trabalhador.

Nas palavras de Barros (2009, p.183):

O termo 'assédio moral' foi utilizado pela primeira vez pelos psicólogos e não faz muito tempo que entrou para o mundo jurídico. O que se denomina assédio moral, também conhecido como mobbing (Itália, Alemanha e Escandinávia), harcèlement moral (França), acoso moral (Espanha), terror psicológico ou assédio moral entre nós, além de outras denominações, são, a rigor, atentados contra a dignidade humana e se manifestam, de início, na família e na escola, quando se confrontam, respectivamente, filhos e alunos com predileções ostensivas. Ora, a exibição de valores, o relato do brilho e da glória de uns com ostracismo do outro gera ciúmes, inveja e rivalidades

Para Souza (2013), o assédio moral é tão antigo quanto o próprio trabalho. Porém, ganhou relevância nas últimas décadas com a divulgação de pesquisas realizadas na área da Psicologia, desenvolvidas na Europa.

\subsection{Conceito de Assédio Moral}

O assédio moral é caracterizado por comportamentos humilhantes e abusivos (palavras, gestos, e ações) que prejudicam a integridade física e psíquica da vítima e que ocorrem de maneira repetitiva e prolongada, transformando negativamente o ambiente de trabalho. As agressões ocorrem tanto por parte de superiores hierárquicos (chefes) quanto por parte de colegas do mesmo nível hierárquico (mesmo cargo ou função).

Sena (2014) caracteriza o assédio moral como:

uma transgressão, seja física, seja mental, que se encontra espalhado por todos os campos, como - escolar, familiar, ambiente de trabalho, relacionamento, dentre tantos outros, afinal, entre todos os povos, entretanto, cada um com as suas características que são típicas de cada povo, principalmente, da cultura.

Para Leymann (1996, p.66): “o assédio moral consiste em um psicoterror. Ocorrendo, este, no ambiente de trabalho por uma comunicação agressiva e não ética direcionada a um indivíduo ou mais". O psicólogo afirma que a continuação e extensão longa dessas práticas agressivas resultam em tortura mental, psicossomático e social as vítimas.

No mesmo raciocínio, Hirigoyen (2005) conceitua o assédio moral em local de trabalho:

temos que entender toda e qualquer conduta abusiva manifestando-se, sobretudo, por comportamentos, palavras, gestos, escritos, que possam trazer dano à personalidade, à dignidade ou à integridade física ou psíquica de uma pessoa, pôr em perigo seu emprego ou degredar o ambiente de trabalho.

Durante os debates sobre assédio moral, surgiram diversos conceitos acerca do tema. O sueco Leymann, citado por Menezes (2002, p. 142), como o pioneiro no assunto, conceitua o assédio moral como:

A deliberada degradação das condições de trabalho através do estabelecimento de comunicações não éticas (abusivas), que se caracterizam pela repetição, por longo tempo, de um comportamento hostil de um superior ou colega (s) contra um indivíduo que apresenta como reação de um quadro de miséria física, psicológica e social rivalidades.

Conforme conceituam as doutrinas, este fenômeno do assédio moral consiste em costumes utilizados por uma pessoa ou um grupo de pessoas que tem propósito de praticar a brutalidade psicológica de modo profundo, extensivo e vulgar.

Consiste em uma conduta abusiva que se revela sob a 
forma de comportamentos, de atitudes, de ações verbais ou escritas, públicas ou não, que têm a capacidade de oprimir, causando danos à dignidade, para sua personalidade ou para integridade psíquica, tendo como consequência natural de desgaste e repulsa pelo ambiente de trabalho.

Importante enfatizar que em todas as normas que buscam o conceito do assédio moral, termos como relação hierárquica, pressão psicológica, humilhação repetição de abusos são os mais frequentes.

Alkimin (2010, p.61) descreve o assédio:

[...] perseguir com insistência, importunar, molestar, com pretensões insistentes; ao passo que a expressão moral pode ser compreendida em seu aspecto filosófico, referindo-se ao agir ético, ou seja, de acordo com as regras morais ou normas escritas que regulam a conduta na sociedade, o ser e deverser, visando praticar o bem e evitar o mal para o próximo.

Em acórdão 0000793-14.2011.5.03.0108 RO - 9a Turma, proferido pelo Tribunal Regional do Trabalho da $3^{\text {a }}$ Região a Desembargadora Camilla G.Pereira Zeidler definiu o assédio moral como:

A conduta abusiva, de natureza psicológica, que atenta contra a dignidade psíquica do indivíduo, de forma reiterada, tendo por efeito a sensação de exclusão do ambiente e do convívio social. Trata-se, em outras palavras, da repetição de condutas abusivas por parte do empregador ou preposto, agredindo sistematicamente o empregado e provocandolhe constrangimentos e humilhações, com a finalidade de desestabilizá-lo em seu aspecto emocional e excluí-lo de sua posição no emprego.

Segundo Barreto (2000), no trabalho, o assédio moral é reconhecido por atos e comportamentos agressivos, que visam desmoralização profissional, desqualificação, desestabilização emocional e moral dos assediados, tornando o ambiente de trabalho desagradável, insuportável e hostil. Enfim, esta conduta no ambiente de trabalho consiste na perseguição com insistência à vítima. Nesse sentido, o assédio moral é configurado como ransgressão, seja essa física ou mental, por meio de palavras, gestos ou escritos trazendo dano para a saúde do empregado.

\subsection{Condutas que Configuram o Assédio Moral}

Muitas são as condutas agressivas praticadas pelos assediantes no ambiente de trabalho, visto que a maioria dessas é suportada pelos empregados, tendo a necessidade de manter o emprego ou por medo de represália.

$\mathrm{O}$ assédio, no ambiente de trabalho, se configura a seguir em algumas dessas condutas agressivas, expostas de acordo com a sua especificidade.

A danificação das condições de trabalho tem por objetivo prejudicar a vítima do ambiente de trabalho, quem pratica o assédio moral faz-lhe críticas, repreensões, além de comportamentos que prejudicam a autoestima e dignidade da vítima, chegando ao ponto de se considerar incompetente e, às vezes, culpada, diante da forma com que o assediante age, algumas dessas práticas são: retirar da vítima a autonomia;

não lhe transmitir mais informações úteis para a realização de tarefas;

- contestar sistematicamente todas as suas decisões;

criticar seu trabalho de forma injusta ou exagerada;

privá-lo do acesso aos instrumentos de trabalho: telefone,

fax, computador etc.;

- retirar o trabalho que normalmente lhe compete;

dar-lhe permanentemente novas tarefas;

atribuir-lhe proposital e sistematicamente tarefas superiores as suas competências;

atribuir-lhe proposital e sistematicamente tarefas superiores as suas competências;

pressioná-la para que não faça valer seus direitos (férias, horários, prêmios);

agir de modo a impedir que obtenha promoção;

- atribuir à vítima, contra a vontade dela, trabalhos perigosos;

atribuir à vítima tarefas incompatíveis com sua saúde;

- causar danos em seu local de trabalho;

- dar-lhe deliberadamente instruções impossíveis de executar; não levar em conta recomendações de ordem médica indicadas pelo médico do trabalho;

induzir a vítima ao erro (HIRIGOYEN, 2005, p. 108).

Com relação ao atentado contra a honestidade do trabalhador, considera-se toda prática de conduta, atitude, palavra ou escrito no intuito de vexá-lo, se traduz em atentando perante a dignidade do trabalhador. Nesse sentido se tem ainda algumas condutas feitas pelos assediantes sendo essas as insinuações hostis, gestos de desprezo (murmúrio, risadas, falatório, etc.). Há ainda comentários irônicos ou sarcásticos para repreender a vítima; rumores a respeito da honra e boa fama da vítima; desqualificação diante dos colegas, superiores ou subordinados; utilização constante de termos ou gestos obscenos ou degradantes; atos vexatórios relacionados com a esfera privada do trabalhador, consistentes na discriminação sexual, de raça, língua e religião; críticas ou brincadeiras sobre deficiência física ou de seu aspecto físico; atribuição de tarefas humilhantes (HIRIGOYEN, 2005).

\subsection{Sujeitos do Assédio}

O gênero do assédio moral está na constatação dos sujeitos desta prática, na qual os conceitos de empregado e empregador versados pela Consolidação das Leis do Trabalho, nos artigos $2^{\circ}$ e $3^{\circ}$.

Art. $2^{\circ}$ - Considera-se empregador a empresa, individual ou coletiva, que, assumindo os riscos da atividade econômica, admite, assalaria e dirige a prestação pessoal de serviço.

$\S 1^{\circ}$ - Equiparam-se ao empregador, para os efeitos exclusivos da relação de emprego, os profissionais liberais, as instituições de beneficência, as associações recreativas ou outras instituições sem fins lucrativos, que admitirem trabalhadores como empregados.

$\S 2^{\circ}$ - Sempre que uma ou mais empresas, tendo, embora, cada uma delas, personalidade jurídica própria, estiverem sob a direção, controle ou administração de outra, constituindo grupo industrial, comercial ou de qualquer outra atividade econômica, serão, para os efeitos da relação de emprego, solidariamente responsáveis a empresa principal e cada uma das subordinadas.

Art. $3^{\circ}$ - Considera-se empregado toda pessoa física que prestar serviços de natureza não eventual a empregador, sob a dependência deste e mediante salário. 
Qualificadas as partes na relação de emprego se tem a imagem do agressor que, geralmente, está na pessoa do empregador, por aquele ter o poder de direção e controle na relação de trabalho ou emprego.

Conforme estabelecido no Código trabalhista, a subordinação é um dos requisitos da relação de emprego, o que é hierárquico; colega de serviço ou subordinado em relação ao superior hierárquico". não pode ser considerado como poder amplo, absoluto. Nas palavras de Alkimin (2010, p.55): "o sujeito ativo é o acossador, assediador ou agente, empregador ou qualquer superior".

Por ter uma superioridade natural, o agressor é aquele que utiliza meios hostis, atitudes ou gestos repetitivos, sendo a agressão pública ou discreta com o objetivo da vítima se sentir inferior, humilhada e incapaz.

O fato do empregador estar na posição de superioridade na premissa de subordinação, o agressor pode ser também um colega que esteja na mesma posição da vítima, e que atua sobre a vítima deixando assim o ambiente de trabalho desgastado e humilhante. Alguns motivos como a competição, a rivalidade, a antipatia ou ciúmes, são requisitos que geram na vítima a humilhação e repulsa pelo trabalho. A vítima desse terror é empregado que sofre as agressões reiteradas, agressões que comprometem a sua dignidade profissional e pessoal. As consequências estão como pedido de demissão ou a insatisfação pelo trabalho, queda no seu rendimento, além de dano à saúde física e mental do empregado, que em algumas situações gera afastamentos e incapacidade para desempenhar seu trabalho. A vítima do assédio moral se destaca por não possuir a condição do assediador. No entanto, a pessoa que é assediada é aquela que está bem relacionada, bem desenvolvida em seu trabalho.

Guedes (2003, p 69) faz as seguintes observações:

A vítima do terror psicológico no trabalho não é o empregado desidioso, negligente. Ao contrário, os pesquisadores encontraram como vítimas justamente os empregados com um senso de responsabilidade quase patológico; são pessoas genuínas, de boa-fé, a ponto de serem consideradas ingênuas no sentido de que acreditam, nos outros e naquilo que fazem; geralmente são pessoas bem-educadas e possuidoras de valiosas qualidades profissionais e morais. De um modo geral, a vítima é escolhida justamente por ter algo mais. E é esse algo mais que o perverso busca roubar, ou simplesmente não se enquadra nos novos padrões de "modernização" da empresa.

As manobras perversas reduzem a autoestima, confundem e levam a vítima a desacreditar de si mesma e a se culpar. Fragilizada emocionalmente, acaba por adotar comportamentos induzidos pelo agressor. A vítima é inocente, mas as testemunhas da agressão desconfiam dela. Seduzido e fascinado pelo perverso, o grupo não crê na inocência da vítima e acredita que ela haja consentido e, consciente ou inconscientemente, seja cúmplice da própria agressão.

Portanto, o assediado passa a ser discriminado no âmbito do trabalho, sendo submetido a situações humilhantes e desprezíveis, o que gera um sentimento de rejeição comprometendo a saúde física e psíquica, interferindo no convívio familiar e social.

\subsection{Tipos de Assédio}

Conceituado anteriormente o assédio moral atinge a pudor físico e psíquico do empregado com a intenção de prejudicar. No assédio moral existe a discriminação e não aceitação da diferença. Neste contexto existem vários tipos de assédio moral, assédio vertical descendente, (que ocorre dos superiores em relação aos subordinados) horizontal, (de um ou mais colegas em relação a outro colega), vertical ascendente (de um subordinado em relação superior hierárquico) (SENA, 2014). Discorreremos sobre cada um deles.

\subsubsection{Vertical descendente}

A própria expressão é notável que parte de cima para baixo, ou seja, dos superiores (presidentes, mantenedores, gerente, assessor), para os subordinados. Nessa relação se encontra o mais comum caso de assédio moral. Os superiores utilizam desse privilégio que detém para intimidar os seus subordinados.

De acordo com Alkimin (2013, p.61):

[...] o assédio moral vertical descendente, é proveniente do empregador, compreendido na expressão do empregador propriamente dito, bem como qualquer outro superior hierárquico (diretor, gerente, chefe, supervisor), que receba uma delegação do poder de comando.

A autora afirma que este assédio pode ser denominado como estratégia para redução no quadro de funcionários, fazendo com que o empregado peça demissão (ALKIMIN, 2013). Este é o clássico assédio moral que ocorre do superior para o subordinado, podendo ser praticado para o empregado pedir dispensa forçada.

Vejamos a jurisprudência

ASSÉDIO MORAL - ADESÃO PDV - PRESSÃO PSICOLÓGICA - CONFIGURAÇÃO. Adesão ao PDV deve ser espontânea, de acordo com a conveniência do trabalhador, livre de pressão. O reclamante não aderiu ao PDV, tendo sido colocado em 'licença remunerada', por trinta dias, prorrogada sucessivamente até culminar com o desligamento imotivado. Nesse ínterim, recebeu vários 'convites' aderir ao Plano. Evidente que a licença, palestras, cartilhas, 'Disque PDV', demonstrativo das verbas, formulários de inscrição etc., tinham o propósito de 'convencer' o reclamante a aderir o PDV. (TRT 15ª Reg. - RO 2170-2003-001- 15-00-4 - 'Ac. 45023/05 - PATR, $11^{\text {a }}$ Câmara' - Rel. Juiz Edison dos Santos Pelegrini. DJSP 16.9.05, p. 58.

Portanto, as várias formas de empregador agredir o empregado para esse pedir esse desligamento forçado. No contexto atual é o que mais ocorre, pois os subordinados são agredidos pelos empregadores e superiores, sendo obrigados a aceitar tudo para a manutenção do emprego.

\subsubsection{Horizontal}

Nesee caso é importante destacar que não há subordinação hierárquica, sendo que ocorre o assédio moral entre os colegas da mesma posição dentro da empresa. Este ocorre por meio de 
piadas, isolamento, gestos obscenos, grosserias, brincadeiras desagradáveis. A vítima é colocada em situações humilhantes, comentários ofensivos, sobre a sua vida pessoal ou acusações que podem prejudicar sua imagem perante a empresa.

\section{Pamplona Filho (2008) comenta que:}

Assim como no vertical, a conduta assediadora pode ser exercida por uma ou mais pessoas contra um trabalhador ou um grupo destes, desde que, seja este grupo de mesmo grau hierárquico, determinado ou determinável, não se admitindo a indeterminabilidade subjetiva (exemplo: toda a coletividade). Afinal, a conduta hostil e excludente do assédio moral, diante de sua característica danosa, será sempre dirigida a um funcionário específico ou a um grupo determinado para atingir sua finalidade.

\section{Guedes (2003, p. 36) caracteriza como:}

[...] a ação discriminatória é desencadeada pelos próprios colegas de idêntico grau na escala hierárquica. Os fatores responsáveis por esse tipo de perversão moral são a competição, a preferência pessoal do chefe porventura gozada pela vítima, a inveja, o racismo, a xenofobia e motivos políticos, a vítima pode ser golpeada por um só colega ou por vários colegas de trabalho.

É notável que neste tipo de assédio é no que concerne a competição, em que os superiores colocam os empregados para cumprir determinadas metas acabem gerando essas práticas para alcançar os objetivos, prejudicando a convivência entre si.

Portanto, se verifica que este assédio pode ser praticado de forma individual ou coletiva, e pode acontecer de um ou vários empregados em face de um empregado ou de um grupo de empregados.

\subsubsection{Vertical ascendente}

Entre as espécies de assédio moral, a vertical ascendente é a mais difícil de acontecer. Este tipo de assédio ocorre quando a prática parte de um ou mais empregados inferiores para o superior hierárquico, isto ocorre de ordem abusiva, mandados que consideram autoritários.

Sena (2014) comenta que:

Muitas das vezes, o assédio moral na espécie vertical ascendente aparece em virtude, também, de recusa por parte do subordinado em ter resistência a cumprir determinada ordem, às vezes, pelo fato de achá-la abusiva, ou ainda, no caso, de ser considerada autoritária. Mas, para muitos o descumprimento de tal ordem é descumprida pelo fato de o superior ser uma pessoa indesejada, malquista por seus subordinados.

Hirigoyen (2002, p.116) distingue estas formas de assédio moral vertical ascendente, como:

a falsa alegação de assédio sexual (com o objetivo de atentar contra a reputação de uma pessoa e desqualificála definitivamente) e as reações coletivas de grupo (a cumplicidade de todo um grupo para se livrar de um superior hierárquico que lhe foi imposto e que não é aceito).

Como essa violência ocorre de baixo para cima, e como o superior hierárquico (vítima) possui o poder de mando e, com isso, o mesmo pode narrar os fatos como lhe convém, comprimindo o assediador (o empregado) a afirmar aquilo que seu superior narra em relação ao acontecimento, porque caso este subordinado discorde do que seu superior relatar faz ameaças de mudança de setor, demissão por justa causa, mudando a história a seu favor, entre outras situações.

\section{Conclusão}

O assédio moral é demonstrado por situações humilhantes, constrangedoras ao empregado sendo colocado a suportar em silêncio todos os insultos e ofensas, sendo o desemprego a ameaça constante no cenário atual.

Discutiram-se as noções sobre o assédio moral, sendo uma violência ocasionada na relação de emprego, que pode ocorrer fora do ambiente de trabalho tendo às vezes danos irreparáveis. O capítulo segundo conceituou, de forma geral, o assédio moral, sendo uma transgressão física ou mental, caracterizado por comportamento humilhantes e abusivos. Preocupou-se em analisar as condutas que configuram o assédio moral. Caracterizaram-se os sujeitos do assédio moral sendo esses na maioria das vezes o empregador por estar na posição superior do empregado, e o sujeito passivo o empregado. Por fim, foram conceituados alguns dos tipos de assédio moral existentes, sendo esses o vertical descendente, o horizontal e vertical ascendente.

A configuração do assédio moral é a continuidade de ações que atentem contra o empregado, alcançando sua honra, levando o mesmo ao descontrole emocional. Esta violência na relação de emprego se configura como uma afronta ao princípio da dignidade da pessoa humana, pois age de forma direta na personalidade do trabalhador.

Esta violência se caracteriza pela repetição dos atos do agressor, que tem o objetivo de minimizar e desvalorizar a vítima, sendo praticado de forma silenciosa, conferindo qualquer reação do trabalhador.

O assédio moral é um assunto recente, mas já vem de antiga realidade na relação de trabalho. Esta ameaça surgiu com a escravidão, em que os escravos já suportavam agressões para sua personalidade. Na atualidade, essa realidade é a moderna organização do trabalho, em que a competição é o principal motivo para a ocorrência desse fenômeno. Nesse sentido, a multiplicação de doenças pode levar a incapacidade do empregado no exercício de sua função.

Durante o estudo do tema se observou que o assédio moral pode ser praticado pelos superiores hierárquicos, empregados a empregados e de empregados para os superiores.

No ordenamento jurídico não existe lei específica que regulamenta o assunto, nos casos que ocorrem esta conduta são julgados através de jurisprudência até que seja aprovada uma medida de coibição para esta conduta.

Para o encerramento do assédio moral é necessário que haja mudanças por parte dos empregados e pela empresa. Estes precisam denunciar estes abusos em todas as suas 
formas de atuação, para que esta modalidade de crime não fique em silêncio. Portanto, conclui-se que havendo sanções mais severas aos condutores dessas ações, diminuiria esse crime. Além, da prática de prevenção por parte das empresas.

\section{Referências}

AGUIAR, A.L.S. Assédio moral. O direito à indenização pelos maus-tratos e humilhações sofridos no ambiente do trabalho. São Paulo: LTr, 2006.

ALKIMIN, M.A. Assédio moral na relação de trabalho. Curitiba: Juruá, 2010.

AMORIM, C.F.S. O assédio moral nas relações de trabalho. Âmbito Jurídico, v.16, n.118, 2013.

BARRETO, M.A.A. Assédio moral no trabalho: responsabilidade do empregador - perguntas e respostas. São Paulo: LTr, 2007.

BARROS, A.M. Proteção à intimidade do Empregado. São Paulo: LTR, 2009.

GUEDES, M.N. Terror psicológico no trabalho. São Paulo: LTr,
2003.

HIRIGOYEN, M.-F. Mal-estar no trabalho: redefinindo o assédio moral. Rio de Janeiro: Bertrand Brasil, 2002.

HIRIGOYEN, M.-F. Mal-estar no trabalho: redefinindo o assédio moral. Rio de Janeiro: Bertrand Brasil, 2005.

HIRIGOYEN, M.-F. Assédio moral: a violência perversa no cotidiano. Rio de Janeiro: Bertrand Brasil; 2002.

LEYMANN, H. Mobbing. Paris: SEUIL, 1996.

MENEZES, C.A.C. Assédio moral. Rev. TST, v.68, n.3, p.189195, 2002;

PAMPLONA FILHO, R. Noções conceituais sobre o assédio moral na relação de emprego. Disponível em: $<$ http://jus2.uol. com.br/doutrina/texto.asp?id=8838> Acesso em: 12 dez. 2019.

SOUZA, M.J.R Assédio moral na relação de emprego. 2013. Disponível em: <http://www.jurisway.org.br/v2/dhall.asp?id_ $\mathrm{dh}=10410>$ Acesso em: $12 \mathrm{dez} .2019$.

SENA, G.C. Trabalho. Rev Jus Navigandi, v.19, n.3840, 2014. 